Original Research Paper

\title{
Isolation and Identification of a Bioflocculant-Producing Strain and Application in Rice Vinegar Clarification
}

\author{
Dehui Dai and Weilian Hu \\ School of Biological and Chemical Engineering, Zhejiang University of Science and Technology, Hangzhou 310012, China
}

\author{
Article history \\ Received: 27-09-2020 \\ Revised: 24-12-2020 \\ Accepted: 29-12-2020 \\ Corresponding Author: \\ Weilian $\mathrm{Hu}$ \\ School of Biological and \\ Chemical Engineering, \\ Zhejiang University of Science \\ and Technology, Hangzhou \\ 310012, China \\ Email: weilian89@126.com
}

\begin{abstract}
A bioflocculant-producing bacterium S-3\# was isolated from fresh sand bones 40-50 cm underground in the desert region of China's Ningxia Province. It was identified as Paenibacillus sp. based on 16S rDNA sequence along with its biochemical and morphological characteristics. Chemical analysis found that the bioflocculant from S-3\# is mainly composed of extracellular polysaccharide. Researchers observed no noticeable change (above 91\%) in its flocculating activities in $\mathrm{pH}$ range 2.0-9.0 in kaolin suspensions and hypothesized that it could be useful in clarification of rice vinegar $(\mathrm{pH}$ 2.9-3.5). Using one-factor-at-a-time experiments, dosage of bioflocculant, temperature of flocculation system and metal cations were investigated for their efficacy on rice vinegar clarification. The Box-Behnken design, an experimental design for Response Surface Methodology (RSM), was also used to create a series of 17 runs to optimize the operating conditions. Quadratic regression models with estimated coefficients were developed to describe the suspended particle removals of rice vinegar. Results showed that the optimal flocculation conditions were $3.94 \mathrm{mg} / \mathrm{L}$ bioflocculant, $0.32 \mathrm{mM}$ $\mathrm{CaCl}_{2}$ and flocculation system temperature of $41.5^{\circ} \mathrm{C}$, respectively. These findings were in reasonable agreement with the modeled values. Under these conditions, the increase rate of transmittance $(\lambda=900 \mathrm{~nm})$ of rice vinegar ranged over $240.63 \%$ under these conditions.
\end{abstract}

Keywords: Bioflocculant, Paenibacillus sp., Extracellular Polysaccharide, Vinegar Clarification

\section{Introduction}

Flocculants are widely used in industrial processes, from drinking water purification, wastewater treatment, to downstream processes in fermentation processing (Yang et al., 2016; Gassara et al., 2015; Zhang et al., 2020). They can be divided into three categories: Inorganic flocculants, organic flocculants and bioflocculants (Ji et al., 2010; Polasek 2009; Salehizadeh et al., 2018). While the first two categories are widely used due to their effectiveness and low cost. However, these may include the possibility of fatal diseases resulting from extensive usage of alum and the generation of large amounts of sludge, thus introducing new environmental challenges in treatment, regeneration and reuse. In addition, evidence has shown that the second category of polyacrylamide derivatives is a strong carcinogen and has neurotoxic to humans (Semla et al., 2017). Bioflocculants produced by microorganisms have attracted extensive attention due to their nontoxic, biodegradable and benign properties, still more the degradation intermediates will not cause secondary pollution (Salehizadeh et al., 2018; Ajao et al., 2018). Given these considerations, the use of bioflocculants is expected to increase in various fields as a promising substitute for inorganic and chemically synthetic flocculants.

Vinegars have been used as condiment for many years. They are nutritious and have lots of bioactive compounds including amino acids, polyphenols and tetramethyl pyrazine (Ho et al., 2017). These compounds contribute vinegars its unique flavors and also play important roles in preventing and treating human diseases, such as regulating blood lipid levels, weight loss, antifatigue and antitumor (Petsiou et al., 2014; Baba et al., 2013). However, the richness in proteins and polyphenols can induce haze formation in rice vinegar 
storage, seriously affecting the quality of the product. Currently, the main methods used for vinegar clarification include membrane filtration and flocculation (Lopez et al., 2005; Yin et al., 2019). Among these methods, flocculation is more widely used given its simple process and low cost. Many different types of flocculations have been reported in vinegar clarification, such as bentonite and chitosan (Xiao et al., 2007; Jiang et al., 2013).

Many bacteria have been found to produce bioflocculants and employed in industrial processes (Shahadat et al., 2017). However, maybe due to the limitation of the optimal $\mathrm{pH}$ range, there is no previous report on the application of bioflocculants in vinegar clarification ( $\mathrm{pH}$ 2.9-3.5). Sand bone, made up of sand grains have been found in Ningxia Province, China. The sand bone growing like the roots of tree was 40-60 cm below the ground. It was first reported and named by our research group. In this study, we isolated and identified the novel bioflocculant-producing strain S3\# from it and established its application in rice vinegar clarification. The findings from this work are positive and provide useful information for downstream processes in brewing food.

\section{Materials and Methods}

\section{Materials}

The UNIQ-10 column DNA extraction kit (SK1201), DNA maker (SM0337) and DNA gel recycle and purification kit were purchased from Sangon Biological Engineering Technology, Shanghai, China. The forward primer sequence 7f (5-CAGAGTTTGATCCTGGCT-3) and reverse primer sequence 1540r (5AGGAGGTGATCCAGCCGCA-3) were synthesized by Sangon Biological Engineering Technology, Shanghai, China. Sucrose, sodium nitrate, magnesium sulfate, dipotassium phosphate, hexadecyl pyridinium chloride and other reagents were of analytical grade. Raw rice vinegar produced by submerged fermentation was provided by Zhejiang Wuweihe Food Co., Ltd (Zhejiang, China).

\section{Isolation and Culture of Strain S-3\#}

Bioflocculant-producing strain S-3\# was isolated from fresh sand bones $40-50 \mathrm{~cm}$ underground in the desert region of Ningxia Province, China (Fig. 1 and 2). The enriched medium composition was: $20 \mathrm{~g}$ sucrose, $30 \mathrm{~g}$ sand (selected form sampling site), $0.5 \mathrm{~g} \mathrm{MgSO}_{4}$ . $7 \mathrm{H}_{2} \mathrm{O}, 1.0 \mathrm{~g} \mathrm{NaNO}_{3}, 1.0 \mathrm{~g} \mathrm{~K}_{2} \mathrm{HPO}_{4}, 0.005 \mathrm{~g} \mathrm{FeCl}_{2}, 20 \mathrm{~g}$ agar, $1000 \mathrm{~mL}$ distilled water, with a total $\mathrm{pH}$ of 7.0-7.5. Using a sterilized needle, the brown material in the hollow part of the fresh sand bones was picked out and then was added into the $250 \mathrm{~mL}$ Erlenmeyer flasks containing $50 \mathrm{~mL}$ enriched medium and then incubated at $180 \mathrm{rpm}$ for $72 \mathrm{~h}$ at $28^{\circ} \mathrm{C}$. After that, the sample was spread on the selected agar after a serial of dilution. The composition of the selected agar was: $30 \mathrm{~g}$ sucrose, $0.5 \mathrm{~g}$ $\mathrm{MgSO}_{4} \cdot 7 \mathrm{H}_{2} \mathrm{O}, 2.0 \mathrm{~g} \mathrm{NaNO}_{3}, 1.0 \mathrm{~g} \mathrm{~K}_{2} \mathrm{HPO}_{4}, 0.005 \mathrm{~g}$ $\mathrm{FeCl}_{2}, 18-20 \mathrm{~g}$ agar, $1000 \mathrm{~mL}$ distilled water, with a total $\mathrm{pH}$ of 7.0-7.5. Strains with high viscosity colony were picked out and inoculated into $250 \mathrm{~mL}$ flasks containing $50 \mathrm{~mL}$ isolation medium, then incubated at $180 \mathrm{rpm}$ for $48 \mathrm{~h}$ at $28^{\circ} \mathrm{C}$. $1 \mathrm{~mL}$ culture solution was used to measure the flocculating activity.

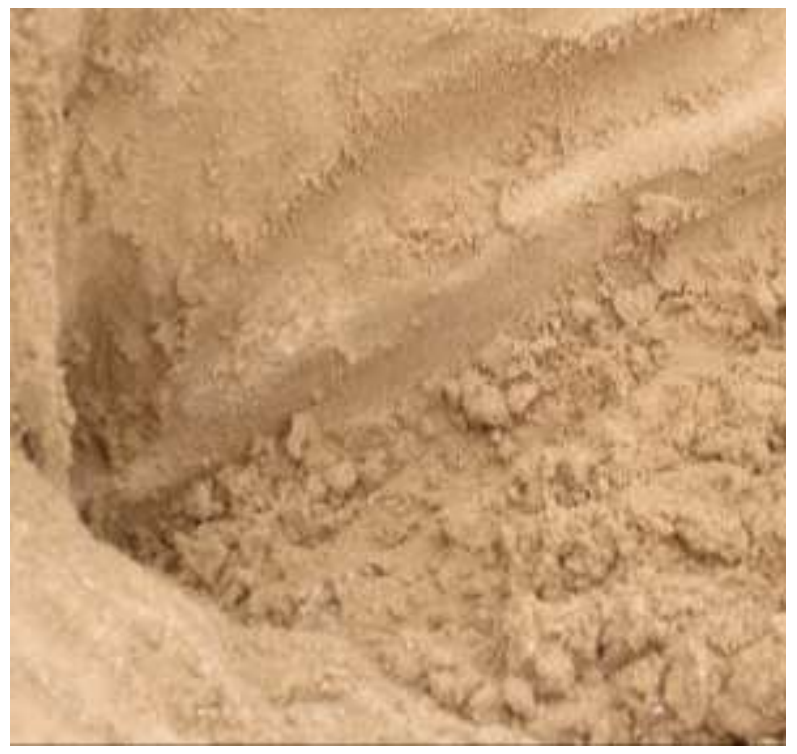

Fig. 1: Sand bone in natural environment (underground $40 \mathrm{~cm}$ )

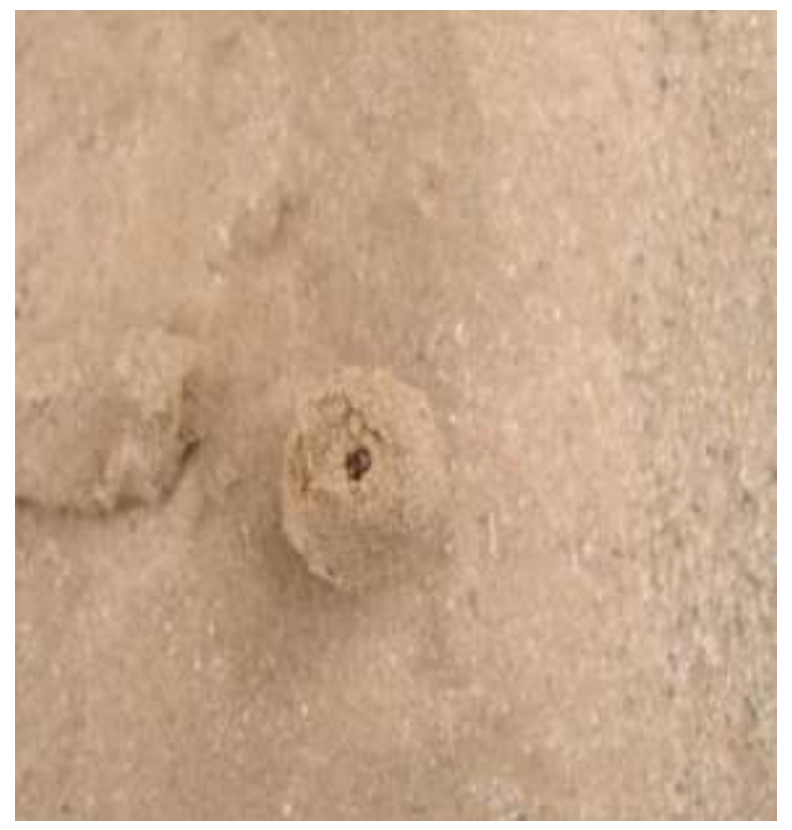

Fig. 2: The cross section of sand bone 


\section{Identification of Bioflocculant-Producing Strain $S$-3\#}

The cell forms and the colony characteristics of strain S-3\# on selected agar were observed after $48 \mathrm{~h}$ of incubation. The strain was identified by $16 \mathrm{~S}$ rDNA sequencing. The genomic DNA of S-3\# was extracted, then PCR amplification of the $16 \mathrm{~S}$ rDNA was carried out using universal primers. The PCR conditions were: Denaturation at $98^{\circ} \mathrm{C}$ for $180 \mathrm{~s}, 98^{\circ} \mathrm{C}$ for $25 \mathrm{~s}$ with 30 cycles, $55^{\circ} \mathrm{C}$ for $25 \mathrm{~s}, 72^{\circ} \mathrm{C}$ for $60 \mathrm{~s}$ and a final extension at $72^{\circ} \mathrm{C}$ for $600 \mathrm{~s}$. PCR products were purified and sequenced. The synthetic sequence was submitted to the GenBank and analyzed using BLAST. Clustal X 2.1 was used to the alignment of relevant sequences. With the neighbour-joining and maximum-parsimony algorithms using MEGA 5, Phylogenetic trees were constructed (Yang et al., 2015).

\section{Determination of Flocculating Activity and $p H$ Stability}

To evaluate the flocculating activity of strain S-3\#, kaolin clay suspension was used. $4 \mathrm{~g}$ of kaolin clay was dissolved in $1 \mathrm{~L}$ distilled water as the Kaolin suspension. $100 \mathrm{~mL}$ of this kaolin suspension was added into a 250 $\mathrm{mL}$ conical flask which has $1 \mathrm{~mL}$ of cell-free supernatant and $3 \mathrm{~mL}$ of $\mathrm{CaCl}_{2}(1 \%$, w/v). The mixture was shaken for $30 \mathrm{~s}$ and then gently poured into a $100 \mathrm{~mL}$ cylinder and stand for $5 \mathrm{~min}$. The clarifying solution was collected and measured its $\mathrm{OD}_{550}$. The control group was done similarly, except that the cell-free supernatant was replaced by the production medium. The Flocculating Activity (FA) was calculated as following (Agunbiade et al., 2018):

$$
F A(\%)=\frac{B-A}{B} \times 100
$$

where, $A$ and $B$ are the absorbance of the sample and control group at $550 \mathrm{~nm}$, respectively.

To figure out the effect of $\mathrm{pH}$ on the flocculating activity, the $\mathrm{pH}$ of kaolin clay suspension was adjusted to 2-10. The initial kaolin suspension ( $\mathrm{pH} 7.5)$ was used as a control group (Pu et al., 2020).

\section{Bioflocculant Purification}

To purify the bioflocculant, an equal volume of distilled water was added into the broth and then centrifuged at $14000 \mathrm{~g}$ for $30 \mathrm{~min}$ to remove the cells. Triple volumes of ethanol $\left(4^{\circ} \mathrm{C}\right)$ were added to the supernatant and then the crude bioflocculant precipitate was dried overnight in a desiccator. Then the crude bioflocculant was dissolved in distilled water and $2 \%$ (w/v) Cetylpyridinium Chloride (CPC) was added until that the insoluble CPC-bioflocculant complex was no longer formed. The precipitate was re-dissolved in saline solution $(0.6 \mathrm{~mol} / \mathrm{L} \mathrm{NaCl})$, Finally, three volumes of ethanol were added to the supernatant and finally was lyophilized to obtain a purified bioflocculant (Salehizadeh and Shojaosadati, 2002). The total sugar content and protein content of the bioflocculant were determined according to the cited literature (Luo et al., 2005; Liu et al., 2010).

\section{Optimization of Flocculating Conditions}

Rice vinegar produced by submerged fermentation was collected and transported to the laboratory using a cooler box containing ice-pack. Transmittance was chosen as the index to measure the flocculating efficiency of the purified bioflocculant in rice vinegar (Xiao et al., 2007). $1 \mathrm{~mL}$ the purified bioflocculant solution was added into $100 \mathrm{~mL}$ of rice vinegar. The mixture was agitated for $2 \mathrm{~min}$ and was allowed to standing for $10 \mathrm{~min}$ and then the supernatant was taken for analysis. The transmittance of the supernatant was measured using at $900 \mathrm{~nm}$. The control group was prepared by same procedure except that the distilled water was replaced by the sample solution.

The Increase Rate of Transmittance (IRT) was calculated as follows:

$$
\operatorname{IRT}(\%)=\frac{B-A}{A} \times 100
$$

where, $A$ initial value; $B$ value after the flocculation treatment.

The bioflocculant dosage, the temperature of the flocculation system and the concentration of cations were the key factors affecting the flocculation efficiency. To get the optimal flocculating conditions of the bioflocculant applied in clarification of rice vinegar, Single factor experiments were used to examine the effects of bioflocculant dosage and various salts and temperature of the flocculation. Based on the above works, these factors were further optimized using a BoxBehnken design. The trials were conducted three times and the average IRT at each run was used as the response variable. The data obtained from RSM was analyzed according to the second-order polynomial equation with the Design-Expert 10.0 software. ANOVA and diagnostics analysis were used to evaluate the quality of analysis model (Wang et al., 2013).

\section{Results and Discussion}

\section{Isolation and Identification of Bioflocculant- Producing Strain}

One bacterium with high viscosity colony (named S-3\#) was obtained in the assessment with the limited conditions. The colony of strain S-3\# was found to be 
smooth, round, transparent, thick and colorless after $48 \mathrm{~h}$ of aerobic incubation (Fig. 3). Its biochemical and physiological characteristics are: Gram stain (+), peroxidise (-), catalase (-), the Voges-prokauer test (-), Gelatin hydrolysate (-), urease (-), amylolysis (+), hydrogen sulfide (-), indole test (-). Microscopic examination showed that S-3\# was a bacilliform, with thick capsules in its surroundings. The capsule size was 10-20 times larger than their body (Fig. 4).

The $16 \mathrm{~s}$ rDNA sequences of strain S-3\# was determined to be 1458 bp long after the PCR amplification (Fig. 5). Figure 6 was the phylogenetic tree. Based on the morphological characteristics and 16s rDNA sequence analysis, strain S-3\# was identified as Paenibacillus sp.

\section{Flocculating Activity and $\mathrm{pH}$ Stability Assessment}

Flocculating activity of culture broth from the strain S$3 \#$ was tested using the Kaolin suspension method, which was $92.8 \%$ after $48 \mathrm{~h}$ of fermentation. It is much higher than the Klebsiella sp. (86.9\%) (Liu et al., 2014) and the Bacillus megaterium (83.8\%) (Luo et al., 2016). This suggests that the strain $\mathrm{S}-3 \#$ is able to synthesize bioflocculant effectively. The $\mathrm{pH}$ was a key factor that might affect the flocculating activity by changing the ionization degrees of the bioflocculant (Salehizadeh and Yan, 2014). Therefore, different kinds of bioflocculant may have different optimum $\mathrm{pH}$ due to their different compositions. The $\mathrm{pH}$ stability of $\mathrm{S}-3 \#$ was investigated (Fig. 7). The highest flocculating activity was $95.5 \%$ at $\mathrm{pH}$ 5.0. The bioflocculant was quite stable with the $\mathrm{pH}$ between 2.0 and 9.0 , more than $91 \%$ flocculation was achieved at this $\mathrm{pH}$ range. This result was similar to a polysaccharidebased B40 produced by Bacillus velezensis B40, which maintained a 90\% flocculation efficiency at $\mathrm{pH} 1.0-10.0$ (Zaki et al., 2013). However, the optimal pH of most bioflocculants ranged between 5.0 and 8.0, such as Achromobacter sp. (pH 6.0) (Subudhi et al., 2014), Aspergillus flavus sp. (pH 7.0) (Aljuboori et al., 2013) and Halomonas sp. (pH 7.0-8.0) (Shen et al., 2015).

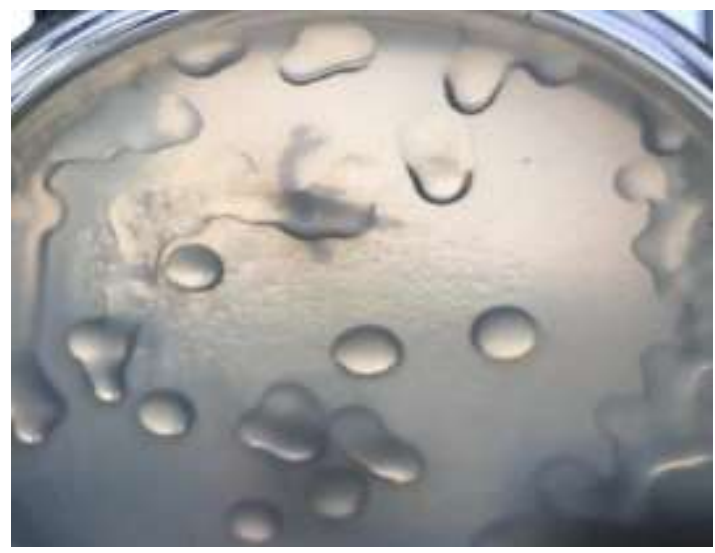

Fig. 3: Colony characteristic of strain S-3\#
The high flocculating activity achieved in a wide $\mathrm{pH}$ range suggests that this bioflocculant could be applied in acidic neutral and alkalescency conditions. But when the $\mathrm{pH}$ was higher than 9.0, its flocculating activity dramatically decreased, this may be due to the bioflocculant having different electric states at different pH (Pan et al., 2009).

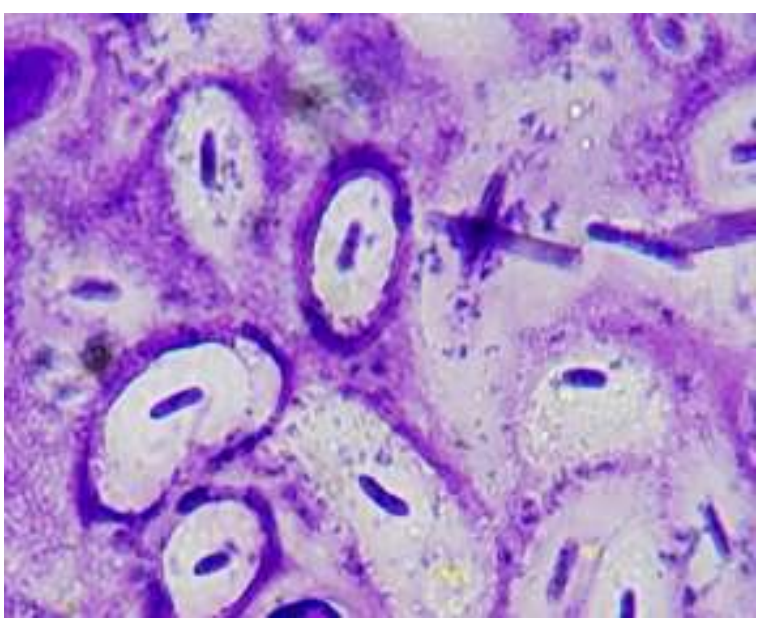

Fig. 4: Microscopic characteristic of strain S-3\# $(\times 1000)$

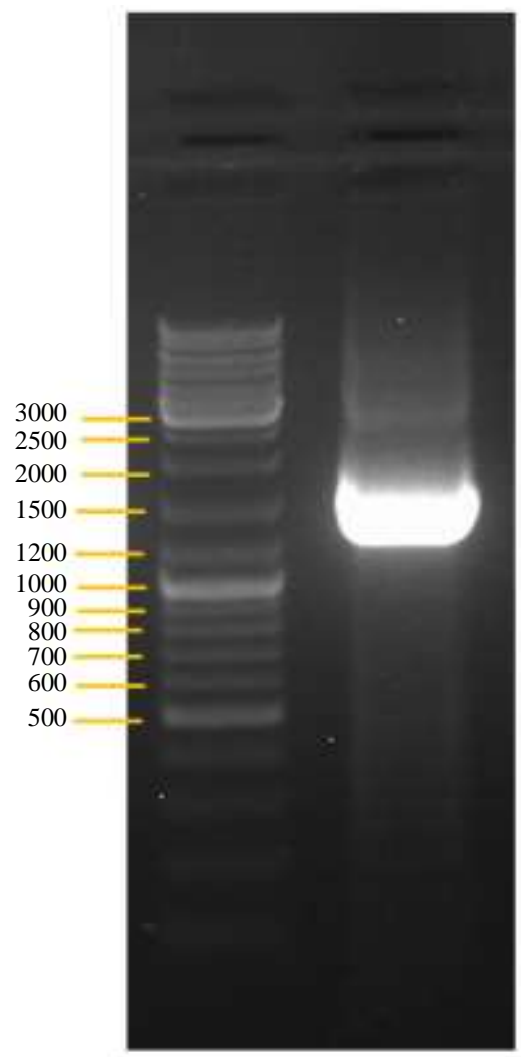

Fig. 5: Result of the PCR product in agarose gel electrophoresis. (Left lane: DNA marker; Right lane: S-3\# PCR product) 


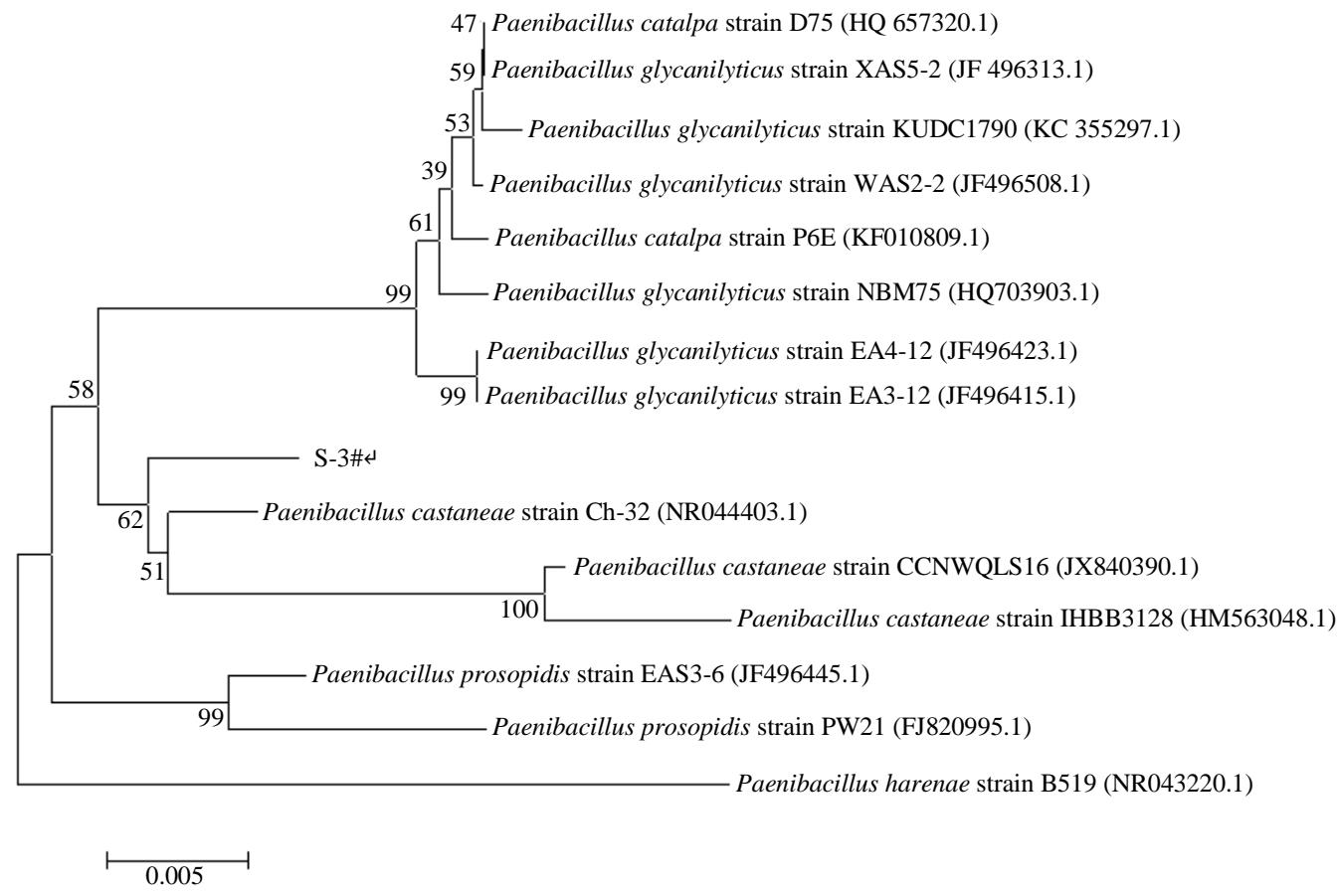

Fig. 6: Neighbour-joing tree based on $16 \mathrm{~S}$ rDNA sequences showing relationship between strain S-3\# and related strains

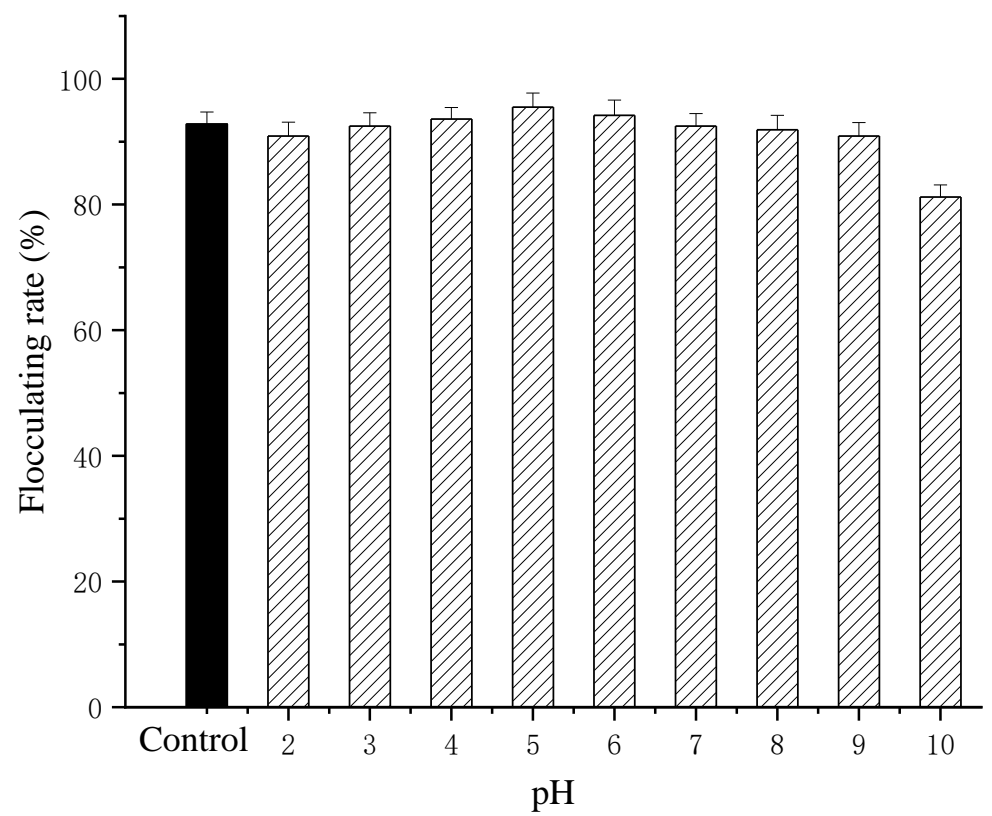

Fig. 7: Effect of $\mathrm{pH}$ on the flocculating rate in kaolin clay suspension

\section{Extraction of the Composition of $S-3 \#$}

About $11.02 \mathrm{~g}$ of purified bioflocculant was obtained from $1 \mathrm{~L}$ of culture broth. It appeared as a white and hygroscopic powder, with $89.1 \%$ (w/w) polysaccharide and $5.8 \%(\mathrm{w} / \mathrm{w})$ protein. Results revealed that it was a polysaccharide-based bioflocculant and the protein content was very low. To evaluate the effect of polysaccharide and protein on the flocculating activity, the Sevag reagent treatment was used to remove the protein in the bioflocculant and the flocculation activities did not significantly declined. This confirmed that extracellular polysaccharides were the key effective component for the flocculation ability. 
Factors Affecting the Bioflocculant on Rice Vinegar Clarification

In this study, we found that S-3\# possesses high flocculating activity in kaolin suspensions and the flocculating activity has no remarkable change at $\mathrm{pH}$ from 2.0 to 9.0. Therefore, it could be used in rice vinegar clarification ( $\mathrm{pH}$ 2.9-3.5).

The effect of bioflocculant dosage (Fig. 8) showed an over $48 \%$ increase rate of transmittance in the range of $1-11 \mathrm{mg} / \mathrm{L}$, with the maximum IRT of $133.62 \%$ observed at optimum bioflocculant dosage of $3.0 \mathrm{mg} / \mathrm{L}$. Figure 8 also showed that the dosage affected the flocculation efficiency. When bioflocculant is insufficient, the bridging phenomena cannot efficiently formed. In contrast, an abundance of negatively charged bioflocculant can cause the repulsion of negatively charged particles and similarly reducing effective volume leading to poorer stability. This is consistent with the flocculation characteristics of polysaccharide flocculants produced by other microorganisms (Gong et al., 2008; Kwon et al., 1996).

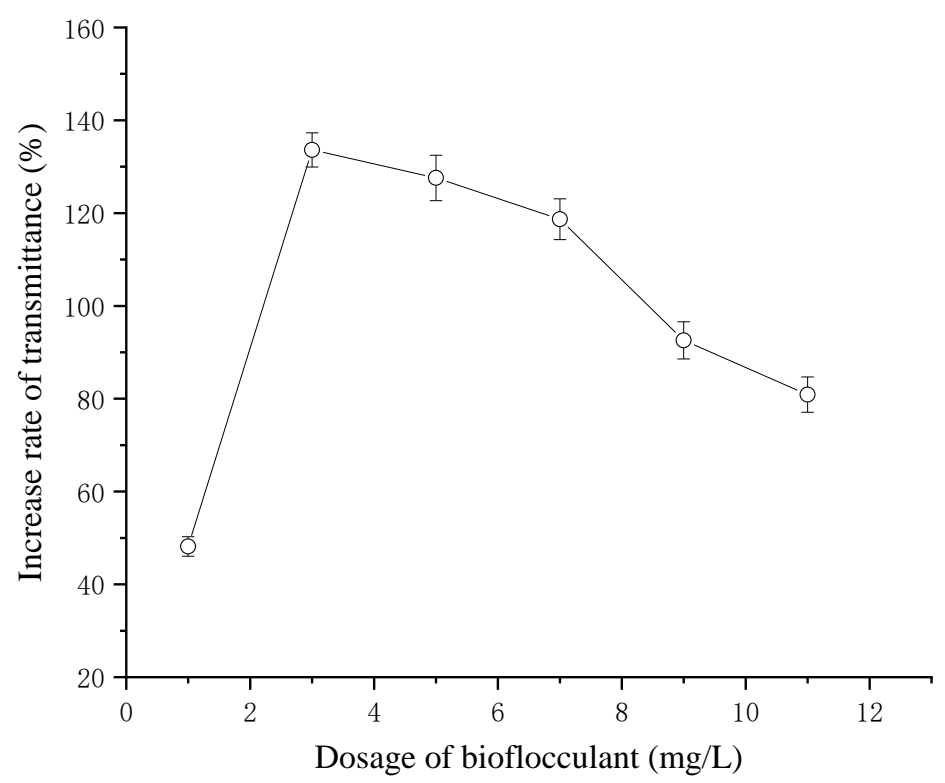

Fig. 8: Effect of dosage of bioflocculant on the increase rate of transmittance

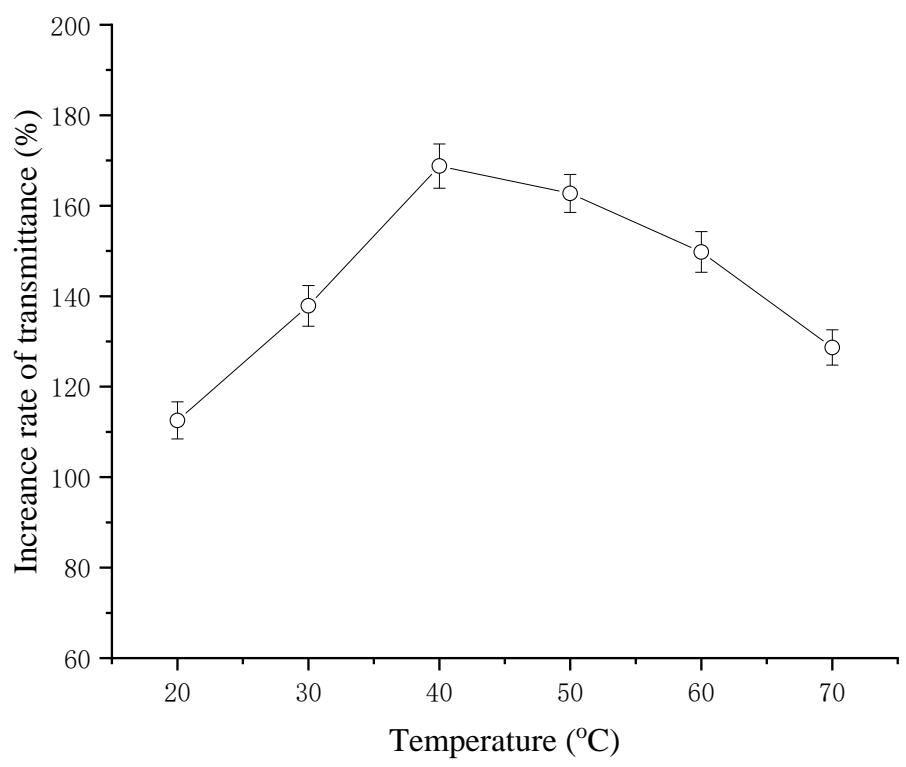

Fig. 9: Effect of temperature on the increase rate of transmittance 
The effect of the temperature of flocculation system was also investigated (Fig. 9). Flocculating activity increased with temperature increase up to the maximum value of $40^{\circ} \mathrm{C}$, thereafter slowly decreased. This could be due to the fact that the high temperature changed the spatial structure of the bioflocculant and induced the lower flocculation efficiency.

To achieve high flocculating activity, metal cations are often added as they may enhance the bridging and neutralization of bioflocculants in the process of flocculation (Sobeck and Higgins, 2002; Kim et al., 2013; Vimala et al., 2020). Figure 10 shows the effect of cations on flocculation. Apparently, trivalent ions $\left(\mathrm{Al}^{3+}\right.$ and $\left.\mathrm{Fe}^{3+}\right)$ and bivalent ions $\left(\mathrm{Ca}^{2+}, \mathrm{Mg}^{2+}\right.$ and $\mathrm{Fe}^{2+}$ ) were more effective than monovalent ions $\left(\mathrm{Na}^{+}\right.$and $\left.\mathrm{K}^{+}\right)$. Similarly, the bioflocculant S-14 produced by Serratiaficaria sp. was effective with metal ions $\left(\mathrm{Ca}^{2+}\right.$ and $\left.\mathrm{Mg}^{2+}\right)$ (Gong et al., 2008).

Given high cost and other considerations $\left(\mathrm{Fe}^{2+}\right.$ is easy to oxidize and bring color into the system, $\mathrm{Al}^{3+}$ is easy to lead to Alzheimer's disease and other disadvantages), $\mathrm{Ca}^{2+}$ appears to be the ideal coagulant aid. In Fig. 11, the high flocculation efficiency was achieved when $\mathrm{Ca}^{2+}$ concentration was $0.3 \mathrm{mM}$.

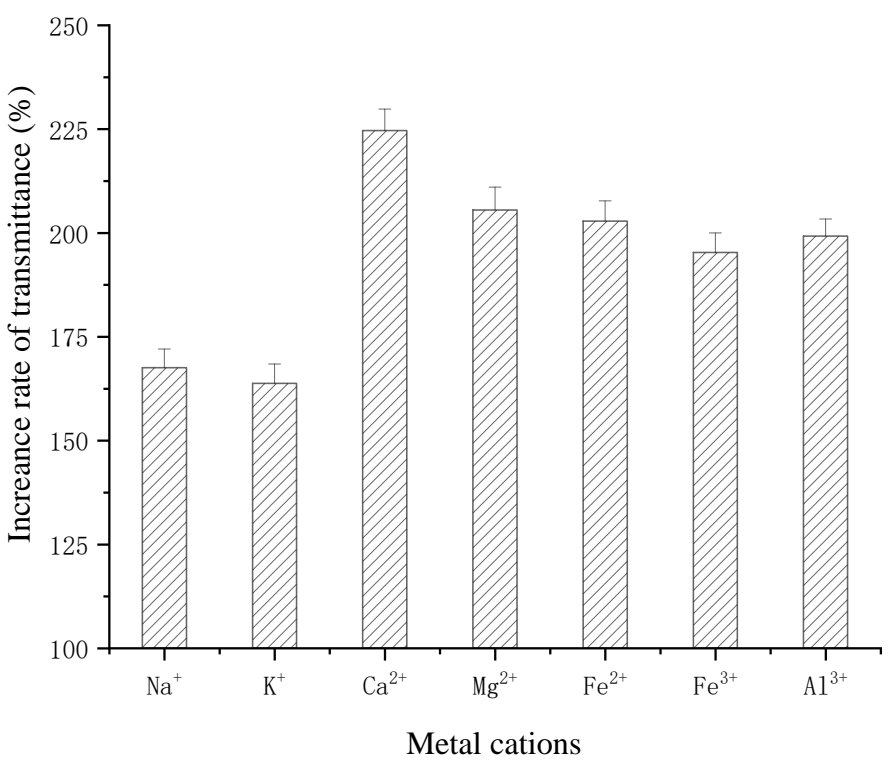

Fig. 10: Effect of metal cations on the increase rate of transmittance

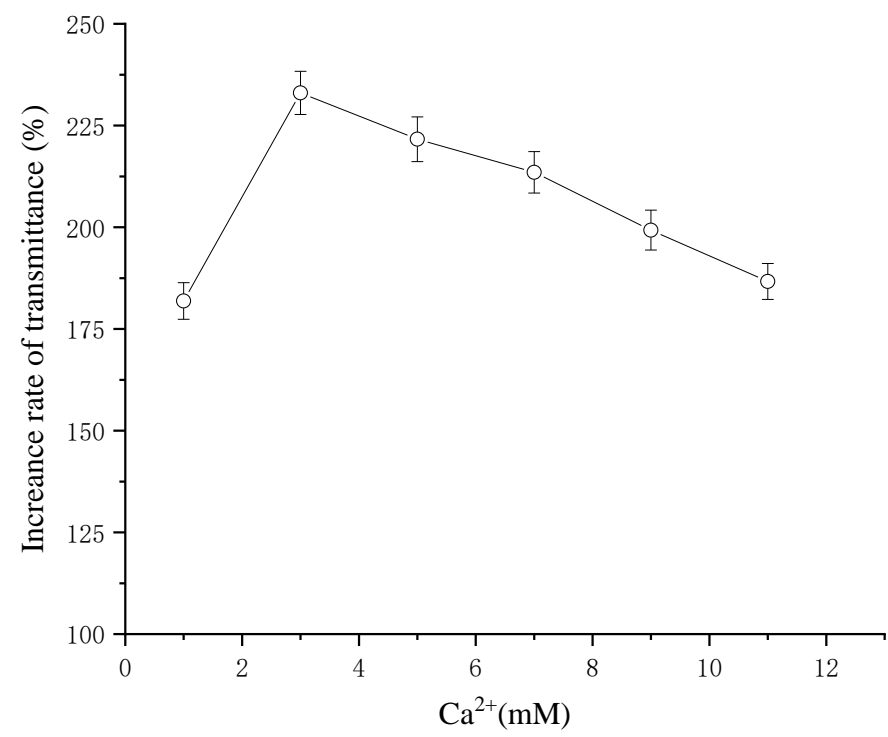

Fig. 11: Effect of $\mathrm{Ca}^{2+}$ on the increase rate of transmittance 


\section{Using RSM for Optimization}

Bioflocculant dosage, flocculation system temperature and $\mathrm{CaCl}_{2}$ were significant factors influencing flocculation. The following experiments using three-level, three-factor Box-Behnken design model with 17 experiments were performed to optimize these factors, the average of both increase rate of transmittance at each run was used as the response variable (Table 1), The statistical testing was carried out with the Fisher's statistical method for Analysis Of Variance (ANOVA) (Table 2). The actual response values from the ANOVA analysis were compared with predicated response values, showing a statistically valid low probability value of $P\left(P_{\text {model }}=0.0009\right)$ indicating that the equation is very reliable in predicting the flocculating efficiency. The lack of fit value was insignificant $(p=0.1292)$, indicating that the equation was adequate for predicting flocculating efficiency. The adequacy of the model was indicated by the determination coefficient $\left(\mathrm{R}^{2}=0.9504\right)$, which accounted for $95.04 \%$ of the response variability.

Table 1: Box-Behnken design and its measured values

\begin{tabular}{lllll}
\hline Run & Dosage of bioflocculant $(\mathrm{mg} / \mathrm{L})$ & $\mathrm{Ca}^{2+}(\mathrm{mM})$ & Temperature $\left({ }^{\circ} \mathrm{C}\right)$ & Increase rate of transmittance $(\%)$ \\
\hline 1 & 3 & 0.3 & 40 & 235.11 \\
2 & 3 & 0.2 & 35 & 205.52 \\
3 & 3 & 0.3 & 40 & 236.62 \\
4 & 2 & 0.3 & 45 & 198.03 \\
5 & 2 & 0.3 & 35 & 194.12 \\
6 & 3 & 0.3 & 40 & 239.22 \\
7 & 4 & 0.4 & 40 & 225.88 \\
8 & 2 & 0.2 & 40 & 203.77 \\
9 & 2 & 0.4 & 40 & 191.63 \\
10 & 4 & 0.3 & 45 & 230.74 \\
11 & 4 & 0.3 & 35 & 202.33 \\
12 & 3 & 0.4 & 45 & 213.51 \\
13 & 3 & 0.4 & 35 & 190.41 \\
14 & 3 & 0.3 & 40 & 234.51 \\
15 & 3 & 0.3 & 40 & 227.55 \\
16 & 3 & 0.2 & 45 & 187.29 \\
17 & 4 & 0.2 & 40 & 226.48 \\
\hline
\end{tabular}

Table 2: ANOVA of flocculating condition

\begin{tabular}{lrrrrr}
\hline Source & SS & DF & MS & F & Probability value \\
\hline Lake of fit & 197.451 & 3 & 65.8169 & 3.4918 & 0.1292 \\
Pure error & 75.395 & 4 & 18.8489 & & 0.0009 \\
Model & 5234.140 & 9 & 581.5711 & 14.9204 & \\
Total & 5506.986 & 16 & & & \\
\hline
\end{tabular}

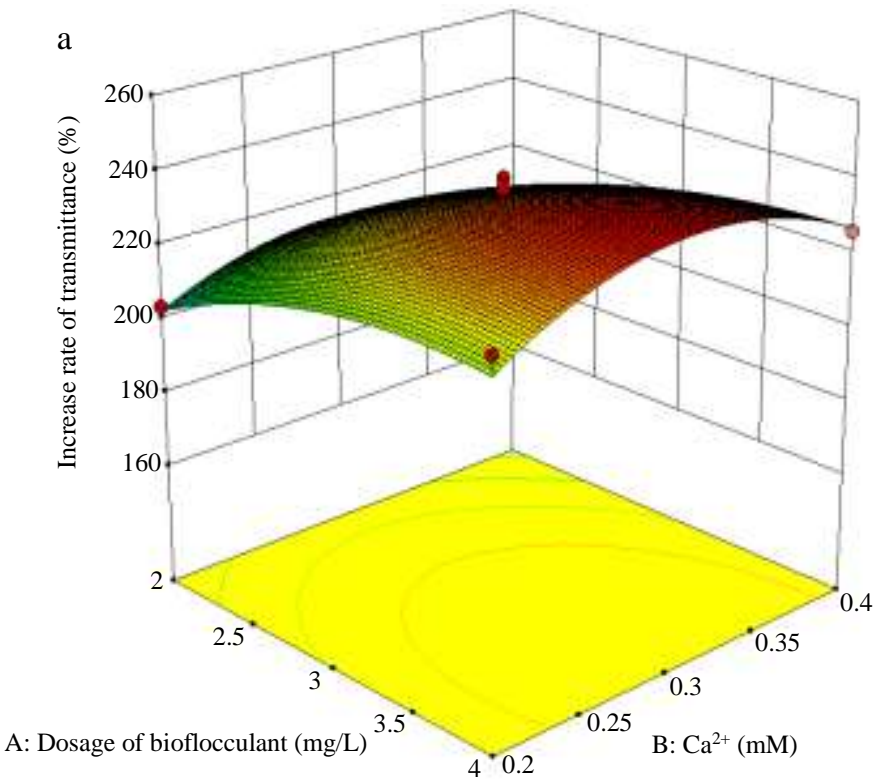



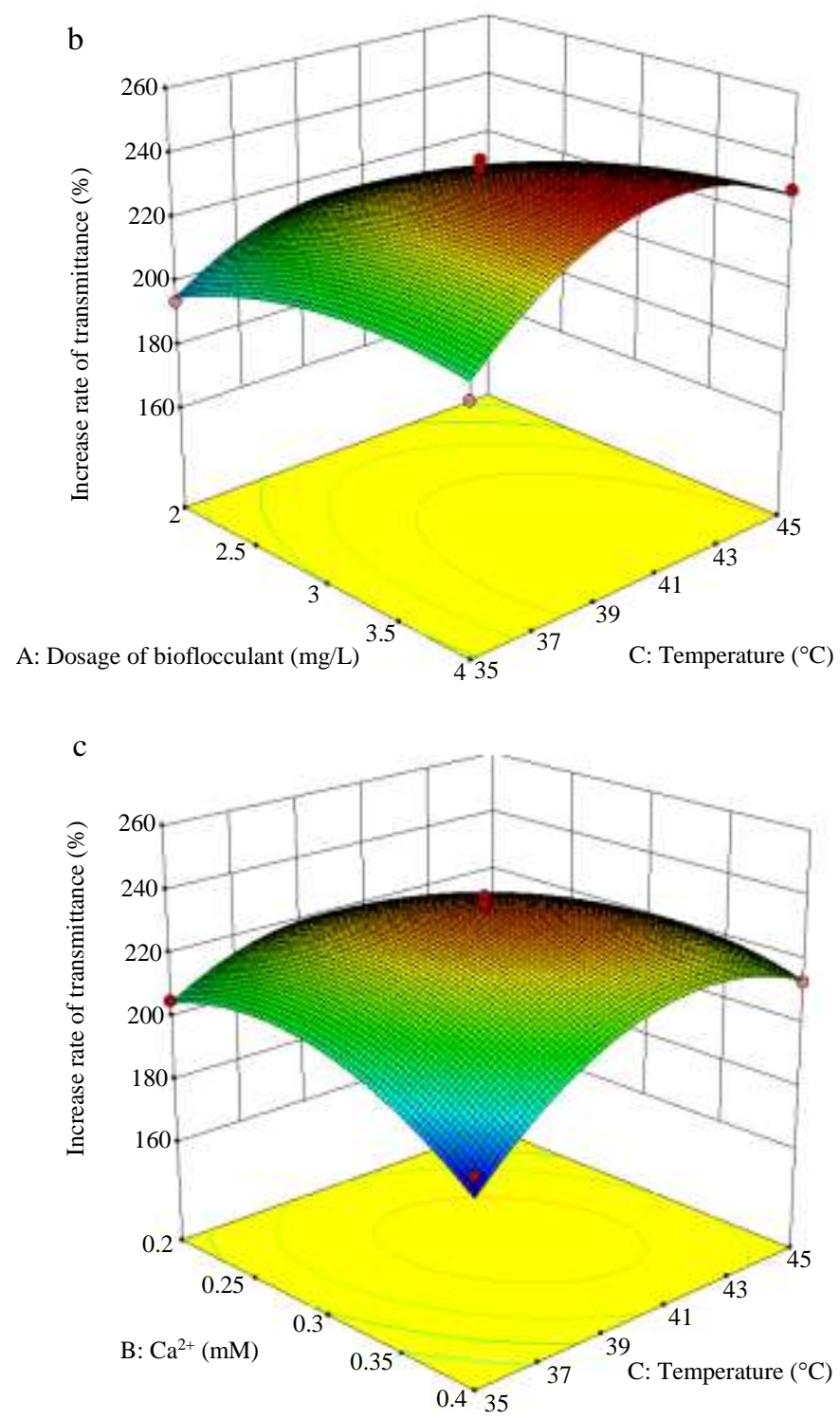

Fig. 12: $(a, b, c)$ Showed the three-dimensional surface response plot and their interactions between the variables

Figure 12 Response surface plots representing the effects of variables on increase rate of transmittance $(\mathrm{Y}$, in percent). A dosage of bioflocculant $(\mathrm{mg} / \mathrm{L})$ and $\mathrm{CaCl}_{2}$ $(\mathrm{mM}) ; \quad \mathrm{b}$ dosage of bioflocculant $(\mathrm{mg} / \mathrm{L})$ and temperature $\left({ }^{\circ} \mathrm{C}\right) ; \mathrm{c} \mathrm{CaCl}_{2}(\mathrm{mM})$ and temperature $\left({ }^{\circ} \mathrm{C}\right)$.

These surface plots, therefore, allow for visualization of the optimum levels of each variable to maximize the flocculating efficiency. The optimal conditions for the bioflocculant were obtained using the "numerical optimization" function within the Design-Expert 10.0. With $3.94 \mathrm{mg} / \mathrm{L}$ bioflocculant, $0.32 \mathrm{mM} \mathrm{CaCl}_{2}$ and flocculation system temperature of $41.5^{\circ} \mathrm{C}$, the highest increase rate of transmittance was predicted to be $241.04 \%$. To verify the reproducibility of the model, all experiments were performed under the optimal conditions. The results showed that the increase rate of transmittance was $240.63,242.51$ and $243.64 \%$. This suggested that the model can reasonably optimize the flocculation conditions and predict the flocculation efficiency for rice vinegar clarification.

\section{Conclusion}

The bacterium S-3\#, isolated from the fresh sand bones, was identified as Paenibacillus sp. It has shown to be able to synthesize bioflocculants effectively. Moreover, the bioflocculant possessed wide range of adaptations at $\mathrm{pH}$ 2.0-9.0. It was found that extracellular polysaccharide was the main constituent of the bioflocculant. The Box-Behnken design showed that 
the optimal flocculation conditions used in rice vinegar clarification were $3.94 \mathrm{mg} / \mathrm{L}$ bioflocculant, $0.32 \mathrm{mM} \mathrm{CaCl} 2$ and flocculation system temperature of $41.5^{\circ} \mathrm{C}$, respectively. The increase rate of transmittance was over $240.63 \%$ under these conditions. Suggesting that the bioflocculant may have promising applications in clarification of brewing food items.

Although bioflocculant has many advantages over other flocculants, the bioflocculant is much expensive due to the high cost of the productive process. To overcome this impediment, future emphasis should be placed on finding out a low-cost medium. The application of bioflocculant in the production of beer will also be studied in the future.

\section{Acknowledgment}

This work was supported by Basic public welfare research program of Zhejiang Province (project number LGG18C010001), P.R. China.

\section{Author's Contributions}

Dehui Dai: Has contributed in the experiment, paper writing and publication.

Weilian Hu: Has contributed in the experiment design and revised the manuscript.

\section{Ethics}

There are no ethical issues to declare that could arise upon the publication of this manuscript.

\section{Reference}

Agunbiade, M., Pohl, C., \& Ashafa, O. (2018). Bioflocculant production from Streptomyces platensis and its potential for river and waste water treatment. Brazilian Journal of Microbiology, 49,731-741.

Ajao, V., Bruning, H., Rijnaarts, H., \& Temmink, H. (2018). Natural flocculants from fresh and saline wastewater: comparative properties and flocculation performances. Chemical Engineering Journal, 349, 622-632.

Aljuboori, A. H. R., Idris, A., Abdullah, N., \& Mohamad, R. (2013). Production and characterization of a bioflocculant produced by Aspergillus flavus. Bioresource technology, 127, 489-493.

Baba, N., Higashi, Y., \& Kanekura, T. (2013). Japanese black vinegar "Izumi" inhibits the proliferation of human squamous cell carcinoma cells via necroptosis. Nutrition and cancer, 65(7), 1093-1097.

Gassara, F., Antzak, C., Ajila, C. M., Sarma, S. J., Brar, S. K., \& Verma, M. (2015). Chitin and chitosan as natural flocculants for beer clarification. Journal of Food Engineering, 166, 80-85.
Gong, W. X., Wang, S. G., Sun, X. F., Liu, X. W., Yue, Q. Y., \& Gao, B. Y. (2008). Bioflocculant production by culture of Serratia ficaria and its application in wastewater treatment. Bioresource technology, 99(11), 4668-4674.

Ho, C. W., Lazim, A. M., Fazry, S., Zaki, U. K. H. H., \& Lim, S. J. (2017). Varieties, production, composition and health benefits of vinegars: A review. Food chemistry, 221, 1621-1630.

Ji, J., Qiu, J., Wai, N., Wong, F. S., \& Li, Y. (2010). Influence of organic and inorganic flocculants on physical-chemical properties of biomass and membrane-fouling rate. Water research,44(5), 1627-1635.

Jiang, X. L., Lu, H. M., Cheng, L., Zhang, L. P., \& Zhang, B. F. (2013). Study on clarification effects of different clarifiers on vinegar. China Condiment, 38, 24-27.

Kim, D. G., Oh, H. M., Park, Y. H., Kim, H. S., Lee, H. G., \& Ahn, C. Y. (2013). Optimization of flocculation conditions for Botryococcus braunii using response surface methodology. Journal of applied phycology, 25(3), 875-882.

Kwon, G. S., Moon, S. H., Hong, S. D., Lee, H. M., Kim, H. S., Oh, H. M., \& Yoon, B. D. (1996). A novel flocculant biopolymer produced by Pestalotiopsis sp. KCTC 8637P. Biotechnology letters, 18(12), 1459-1464.

Liu, J., Ma, J., Liu, Y., Yang, Y., Yue, D., \& Wang, H. (2014). Optimized production of a novel bioflocculant M-C11 by Klebsiella sp. and its application in sludge dewatering. Journal of Environmental Sciences, 26(10), 2076-2083.

Liu, W., Wang, K., Li, B., Yuan, H., \& Yang, J. (2010). Production and characterization of an intracellular bioflocculant by Chryseobacterium daeguense W6 cultured in low nutrition medium. Bioresource technology, 101(3), 1044-1048.

Lopez, F., Pescador, P., Güell, C., Morales, M. L., GarcíaParrilla, M. C., \& Troncoso, A. M. (2005). Industrial vinegar clarification by cross-flow microfiltration: effect on colour and polyphenol content. Journal of food engineering, 68(1), 133-136.

Luo, L., Zhao, Z., Huang, X., Du, X., Wang, C. A., Li, J., \& Xu, Q. (2016). Isolation, identification and optimization of culture conditions of a bioflocculantproducing bacterium Bacillus megaterium SP1 and its application in aquaculture wastewater treatment. BioMed Research international, 2016,2758168.

Luo, P., Luo G. Y., Ji, F. Y., \& Cai, J. W. (2005). Characterization of an extracellular polysaccharide produced by Bacillus sp. RL-2. Journal of Chongqing University (English Edition), 4, 33-37.

Pan, Y., Shi, B., \& Zhang, Y. (2009). Research on flocculation property of bioflocculant PG. a21 Ca. Modern Applied science, 3(6), 106-112. 
Petsiou, E. I., Mitrou, P. I., Raptis, S. A., \& Dimitriadis, G. D. (2014). Effect and mechanisms of action of vinegar on glucose metabolism, lipid profile and body weight. Nutrition reviews, 72(10), 651-661.

Polasek, P. (2009). Optimized conditions for application of organic flocculant aids in water purification. Drinking Water Engineering and Science Discussions, 2(2), 205-229.

Pu, L., Zeng, Y. J., Xu, P., Li, F. Z., Zong, M. H., Yang, J. G., \& Lou, W. Y. (2020). Using a novel polysaccharide BM2 produced by Bacillus megaterium strain PL8 as an efficient bioflocculant for wastewater treatment. International journal of biological macromolecules, 162, 374-384.

Salehizadeh, H., \& Shojaosadati, S. A. (2002). Isolation and characterisation of a bioflocculant produced by Bacillus firmus. Biotechnology Letters, 24(1), 35-40.

Salehizadeh, H., \& Yan, N. (2014). Recent advances in extracellular biopolymer flocculants. Biotechnology Advances, 32(8), 1506-1522.

Salehizadeh, H., Yan, N., \& Farnood, R. (2018). Recent advances in polysaccharide bio-based flocculants. Biotechnology advances, 36(1), 92-119.

Semla, M., Goc, Z., Martiniaková, M., Omelka, R., \& Formicki, G. (2017). Acrylamide: a common food toxin related to physiological functions and health. Physiological research, 66(2), 205.

Shahadat, M., Teng, T. T., Rafatullah, M., Shaikh, Z. A., Sreekrishnan, T. R., \& Ali, S. W. (2017). Bacterial bioflocculants: a review of recent advances and perspectives. Chemical Engineering Journal, 328, 1139-1152.

Shen, L., An, Z., Li, Q., Yao, C., Peng, Y., Wang, Y., \& He, N. (2015). Three-stage fermentation and kinetic modeling of bioflocculant by Corynebacterium glutamicum. Chinese Journal of Chemical Engineering, 23(1), 219-226.

Sobeck, D. C., \& Higgins, M. J. (2002). Examination of three theories for mechanisms of cation-induced bioflocculation. Water research, 36(3), 527-538.

Subudhi, S., Batta, N., Pathak, M., Bisht, V., Devi, A., \& Lal, B. (2014). Bioflocculant production and biosorption of zinc and lead by a novel bacterial species, Achromobacter sp. TERI-IASST N, isolated from oil refinery waste. Chemosphere, 113, 116-124.
Vimala, R. T. V., Escaline, J. L., \& Sivaramakrishnan, S. (2020). Characterization of self-assembled bioflocculant from the microbial consortium and its applications. Journal of Environmental Management, 258, 110000.

Wang, J. N., Li, A., Yang, J. X., Wang, J. H., \& Ren, N. Q. (2013). Mycelial pellet as the biomass carrier for semi-continuous production of bioflocculant. RSC advances, 3(40), 18414-18423.

Xiao, L., Yao, J. H., Leng, Y. W., \& Chen, T. (2007). Study on vinegar clarification by bentonite [J]. China Brewing, 169(4), 27-29.

Yang, M., Liang, Y., Dou, Y., Jia, X., \& Che, H. (2015). Isolation and identification of a bioflocculantproducing strain and optimisation of cultural conditions via a response surface model. Chemistry and Ecology, 31(7), 650-660.

Yang, R., Li, H., Huang, M., Yang, H., \& Li, A. (2016). A review on chitosan-based flocculants and their applications in water treatment. Water research, 95, 59-89.

Yin, X. Q., Lang, F. F., Wang, R. F., \& Hou, H. P. (2019). Clarification process of vinegar with the compound clarifying agent. China Brewing, 38(2), 111-116.

Zaki, S. A., Elkady, M. F., Farag, S., \& Abd-El-Haleem, D. (2013). Characterization and flocculation properties of a carbohydrate bioflocculant from a newly isolated Bacillus velezensis 40B. Journal of environmental biology, 34(1), 51.

Zhang, S., Zheng, H., Tang, X., Zhao, C., Zheng, C., \& Gao, B. (2020). Sterilization by flocculants in drinking water treatment. Chemical Engineering Journal, 382, 122961. 